\title{
Size and structure of the southernmost population of the Endangered Barbary macaque Macaca sylvanus in the western Moroccan High Atlas
}

\author{
Salma Namous, Mohammed Znari, Moulay Abdeljalil Ait Baamrane \\ Mohamed Naimi, Mohamed Aourir, Jan Siess and Soraya Mokhtari
}

\begin{abstract}
The Barbary macaque Macaca sylvanus is imperiled throughout its distribution range in north-west Africa. In the summers of 2009 and 2013 we used the piecewise line-transect distance sampling method to study the southernmost population in the High Ourika valley, in the western High Atlas of Morocco. This rugged mountainous area is dominated by degraded fruit-poor environments, mostly holm oak Quercus rotundifolia forest patches. We located four and two groups in 2009 and 2013, respectively, and estimated population sizes of 122 and 84 individuals. The mean group size was 12 individuals in 2009 and 46 in 2013. The estimated mean density (individuals per $\mathrm{km}^{2}$ ) varied among groups (10-171), with a mean of 27 . The population structure varied significantly among groups and years. Our records comprised 24.8 and $20 \%$ adult males, 24.8 and $22 \%$ adult females, 11 and $13 \%$ subadults, 13 and $17 \%$ juveniles and 26.4 and $26.3 \%$ infants in 2009 and 2013 , respectively. In both years $50-56 \%$ of the population consisted of young individuals (subadults excluded). The mean sex ratio among adults was $1: 1$. The apparent fecundity rate was 1.06 infants per adult female. We propose conservation actions to protect this peripheral population of Barbary macaques.
\end{abstract}

Keywords Density, distance sampling, Macaca sylvanus, Morocco, population structure, Western High Atlas

\section{Introduction}

The Barbary macaque Macaca sylvanus is the only nonhuman primate in Africa north of the Sahara desert (Fooden, 2007). In Morocco the existing populations live in fruit-poor environments and habitats that have been

Salwa Namous, Mohammed Znari (Corresponding author), Moulay Abdeljalit Ait BaAmrane and Mohamed Naimi Biodiversity \& Ecosystem Dynamics Laboratory, Department of Biology, Faculty of Sciences Semlalia, Cadi Ayyad University, P.O. Box 2390, 40000 Marrakech, Morocco

E-mail znarim@gmail.com/znari@uca.ma

MoHAmed AouriR Department of Biology, Faculty of Science, Ibn Zohr University, Agadir, Morocco

JAN SIESS Lycée Agricole Montmorot, Montmorot, France

Soraya Mokhtari Direction Régionale des Eaux et Forêts du Haut-Atlas, Parc National du Toubkal, Marrakech, Morocco

Received 4 March 2016. Revision requested 11 May 2016.

Accepted 22 June 2016. First published online 8 February 2017. significantly modified by people. In the past $40-50$ years the North African population declined from c. 20,00025 ,000 (Taub, 1975; Fa, 1984) to fewer than 10,000-16,000 individuals (Lilly \& Mehlman, 1993; von Segesser et al., 1999). The species is categorized as Endangered on the IUCN Red List (Butynski et al., 2008) and listed in CITES Appendix II (CITES, 2013). The Moroccan population, which is estimated to comprise 5,000-6,000 individuals (Waters et al., 2007), with $65-75 \%$ occurring in the cedar Cedrus atlantica forests of the Middle Atlas, has undergone a significant decline (Camperio Ciani et al., 2005; van Lavieren \& Wich, 2010; Ménard et al., 2013a,b). Before and during the 1970s most of the Moroccan population was concentrated in the Middle Atlas, representing $65 \%$ of the total global population, which was estimated to comprise a maximum of 14,000 individuals at that time (Deag, 1974, 1984; Taub, 1977). In the High Atlas a total of 35 groups were detected in small and fragmented habitats, with 644 individuals counted (El Alami et al., 2013). Fourteen populations were previously reported in the southern Middle Atlas and High Atlas (Cuzin, 2003). In the High Ourika valley, western High Atlas, four groups were reported (Cuzin, 2008).

Distance sampling is the most common method of conducting primate population censuses (e.g. Glenn, 1998; Gonzalez-Kirchner, 1998; Wallace et al., 1998) and has been used to estimate the Barbary macaque population in the Middle Atlas (van Lavieren \& Wich, 2010; Ménard et al., 2013a,b). In areas with rugged terrain, piecewise line transects (Patterson, 2001) can be used as an alternative, as demonstrated for the booted macaque Macaca ochreata in South Sulawesi, Indonesia (Riley et al., 2007). The purpose of the research reported here was to determine the size and structure of the groups and population of Barbary macaques in the High Ourika valley.

\section{Study area}

The High Ourika valley (900-4,100 m elevation) is in the peripheral zone of Toubkal National Park, $65 \mathrm{~km}$ south-east of Marrakech (Fig. 1). The climate is Mediterranean, with a late spring-summer dry season and an autumn-winter to early spring wet season. The mean annual temperature range is $0.5-29.5^{\circ} \mathrm{C}$. The vegetation cover is dominated by forest patches of degraded holm oak Quercus rotundifolia along with other sparsely distributed tree species, and 


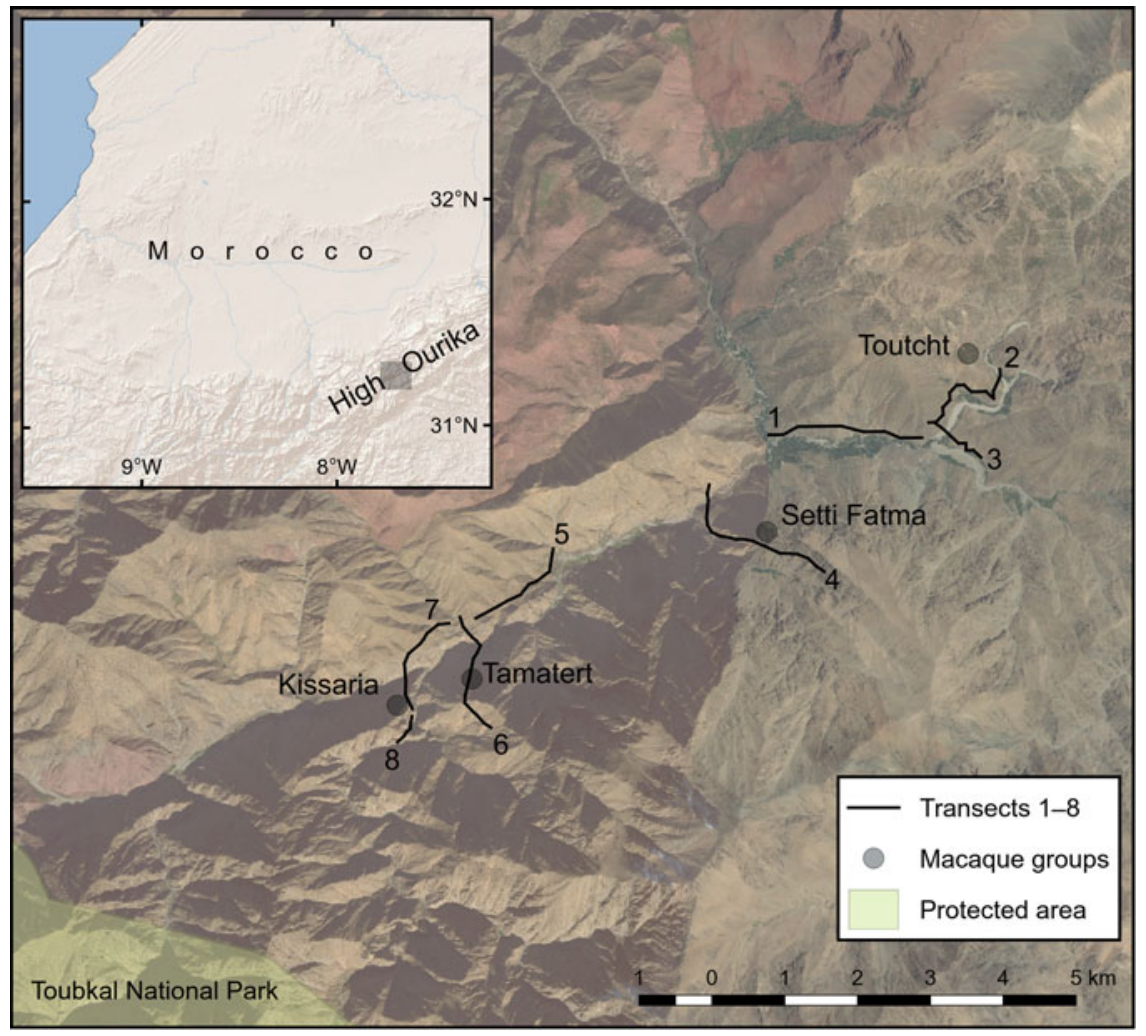

FIG. 1 The locations of eight line transects in the Ourika valley, in the western High Atlas Mountains, Morocco, used to survey for the Barbary macaque Macaca sylvanus. numerous herbaceous species (Ouhammou, 1986). Various fruit trees are cultivated and crop-raiding is frequently a cause of conflict between people and macaques.

\section{Methods}

We surveyed the macaque population using the line transect sampling method, based on the detection probability estimated from the linear distances between detected animals and the observer (Buckland et al., 1993). We used piecewise linear transects, segmented according to the topography; the length of the survey was the sum of all the transect segment lengths (Burnham et al., 1980; Patterson, 2001). We used a global positioning system (GPS) to define eight line transects, with a total length of $25.65 \mathrm{~km}$, along mountain ridges and valleys (Fig. 1) to ensure that the study area was covered systematically, with a total of 138 individual linear segments with an overall mean length of $186 \mathrm{~m}$ (51-509 $\mathrm{m}$ per transect). Based on behavioural observations, the survey was conducted when macaques are most active (06.30-19.30 GMT) in mid Julylate August 2009 and 2013, after the end of the birth season.

An observer walked at a speed of $1 \mathrm{~km} . \mathrm{h}^{-1}$, traversing each transect alternately once or twice per week; each transect survey was replicated three times. Transect surveys were not repeated on the same or consecutive days. For each individual or group detected the observer used a laser rangefinder to measure the distance between the line segment and the individual or the centre of the group, along with the angle between the forward direction of the line segment and the initial location of the macaques. Time, location, number of individuals and group composition were also recorded. The detected groups were identified after being monitored on several occasions during 2009-2013. The sex and age class of observed individuals were determined using criteria defined by Turckheim \& Merz (1984) and used by Ménard et al. (1985). The sex ratio was calculated as the number of adult males to adult females, and the apparent fecundity as the mean number of infants per adult female on the basis of all detected adult females and infants (age up to 1 year).

One key assumption of the line transect method is that all individuals are detected at their initial location. Movement independent of the transect and observer can thus cause substantial bias in abundance estimates and its possible effects should be considered in line transect surveys. It arises from both the detection process inherent in line transect sampling and from the movement characteristics of the target animal. There are currently no analytical methods to deal with this reality; however, bias can be reduced by searching further perpendicularly to the line, searching less far ahead and ignoring individuals that overtake the observer (Glennie et al., 2015).

The data were analysed using Distance v. 5.0 (Thomas et al., 2010), which models the function of the detection, describing the decrease in the probability of detecting the target species according to the perpendicular distance from the transect line. The selection of adequate models among 12 tested was based on the shape of the curve describing the probability of detecting macaques in relation to the recorded 
perpendicular distances, the Akaike information criterion (AIC) value, and the value of a $\chi^{2}$ goodness-of-fit test. The AIC is defined by AIC $=-2^{\star} \log _{e}(\mathrm{~L})+2 p$, where $\mathrm{L}$ is the log-likelihood function evaluated at the maximum likelihood estimates of the model parameter and $p$ is the number of parameters in the model. This criterion provides a method to select the best model from a set of models to fit the data at hand. For a given data set, AIC is computed for each model and the model with the smallest AIC is considered to be the best. The best models have a curve showing a reduction in the probability of detection with increased distance between the observer and the animal, and the lowest AIC value (Buckland et al., 1993, 2001). We conducted ANOVAs to test for significant differences $(\alpha=0.05)$ in mean size and density among groups and years, using STATISTICA 10.o (StatSoft Inc., Tulsa, USA).

\section{Results}

In summer 2009 four groups were identified (86 observations in total) in the study area, from north-east to southwest, as follows: group 1, Tourcht; group 2, Setti Fatma; group 3, Tamatert; and group 4, Kissaria. However, in summer 2013 only groups 2 and 3 were detected $(53$ observations in total; Fig. 2). The mean group size varied from 11 individuals (Kissaria) to 32 (Setti Fatma), and from 27 (Tamatert) to 46 (Setti Fatma), in 2009 and 2013, respectively (Table 1).

We detected 435 and 201 macaques in total in 2009 and 2013, respectively. The effective strip width varied among observation series from 82 to $267 \mathrm{~m}$ (Table 1). Probabilities of the $\chi^{2}$ goodness-of-fit tests for all AIC values of the selected models were $>5 \%$. In summer 2009 the mean density estimates (Table 1) varied significantly among groups (oneway ANOVA: $\left.F_{1,3}=23.12, \mathrm{P}<0.01\right)$ from the north to the south of the study area: $23.63 \pm \mathrm{SD} 6.5$ individuals in Tourcht, $32.45 \pm$ SD 8 in Setti Fatma, $16.46 \pm$ SD 9 in Tamatert, and 11.5 in Kissaria. The mean group size was c. 21 individuals. The corresponding mean densities were $23.74 \pm \mathrm{SD}_{7}, 120.75 \pm \mathrm{SD}_{30}, 17.18 \pm \mathrm{SD}_{2}$ and 10.15 individuals $\mathrm{km}^{-2}$. The total population size was estimated to be 122 individuals, with a mean global density of 42.95 individuals $\mathrm{km}^{-2}$. In summer 2013 the mean group size in Setti Fatma and Tamatert was $48 \pm$ SD 8.5 and $25 \pm$ SD 6.6 individuals, respectively; the total population size was estimated to be 84 individuals. Two-way ANOVAs (Table 2) indicated that mean density and population size estimates were significantly higher in Setti Fatma than in Tamatert in both years, with higher values in both localities in 2013 than 2009. However, there was no significant year-locality interaction for the two variables $(\mathrm{P}>0.05)$, indicating that the effects of these two factors on the mean density and population size were independent.

In 2009 the whole population comprised $49.65 \%$ adults $(24.82 \%$ males and $24.82 \%$ females), $11.03 \%$ subadults,
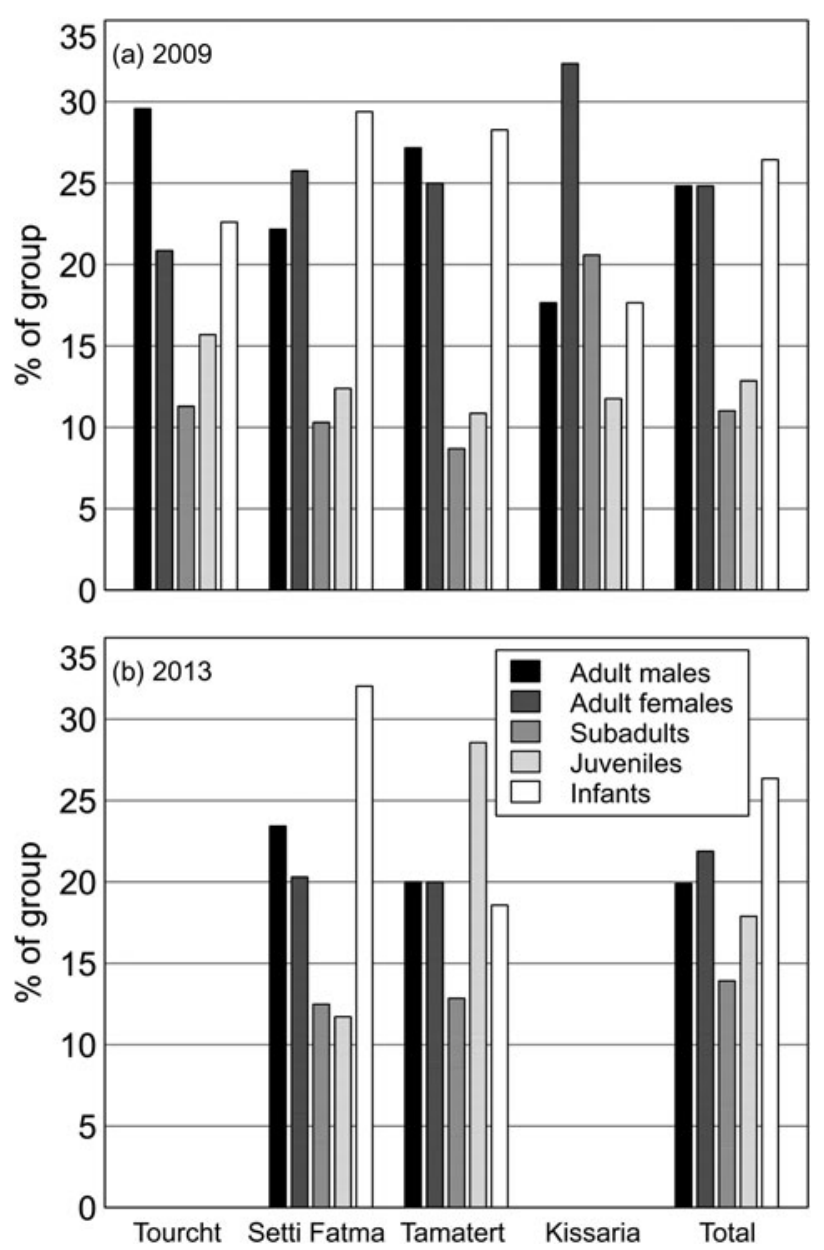

FIg. 2 Age and sex structure of the four Barbary macaque groups located in the High Ourika valley (Fig. 1) in the summer of (a) 2009 and (b) 2013.

$12.87 \%$ juveniles and $26.43 \%$ infants. Male to female-biased adult sex ratios of 1.42 and 0.55 were observed in Tourcht and Kissaria, respectively. In Setti Fatma and Tamatert adult sex ratios were relatively balanced (o.86 and 1.09, respectively). Overall the population showed a balanced adult sex ratio (1.0). The mean apparent fecundity rate was 1.064 infants per adult female. In summer 2013 we recorded lower percentages of adult males and females (19.9 and $21.9 \%$, respectively) and relatively higher proportions of subadults and juveniles (13.9 and $17.9 \%$, respectively) but a similar proportion of infants $(26.36 \%)$. As in 2009 , relatively balanced adult sex ratios were recorded in Setti Fatma and Tamatert (1.15 and 1) and for the two groups combined (o.91). The mean apparent fecundity rate was 1.20 infants per adult female.

\section{Discussion}

This was the first reassessment of group number, size and structure of this peripheral population of Barbary macaques in the High Ourika valley, using the line-transect distance 
TABLE 1 The results of line transect surveys of the Barbary macaque Macaca sylvanus in the High Ourika valley, Western High Atlas, Morocco (Fig. 1) in the summers of 2009 and 2013, with the selected models (key/adjustment) and their AIC values, effective strip width, mean estimated density and coefficient of variation (CV), and the estimated size of each survey group.

\begin{tabular}{|c|c|c|c|c|c|}
\hline Survey & Model $^{1}$ & AIC & $\mathrm{ESW}(\mathrm{m})$ & Density, $\mathrm{km}^{-2}(\mathrm{CV})$ & Group size \\
\hline \multicolumn{6}{|c|}{ Group 1 (Tourcht) 2009} \\
\hline 1 & $\mathrm{U} / \mathrm{C}$ & 100.11 & 94.66 & $30.581(0.171)$ & 30.44 \\
\hline 2 & $\mathrm{U} / \mathrm{SP}$ & 102.95 & 109.91 & $23.013(0.359)$ & 22.91 \\
\hline 3 & $\mathrm{U} / \mathrm{C}$ & 95 & 115.58 & $17.625(0.271)$ & 17.54 \\
\hline Mean \pm SD & & & $106.717 \pm 10.82$ & $23.74 \pm 7(0.267)$ & $23.63 \pm 6.5$ \\
\hline \multicolumn{6}{|c|}{ Group 2 (Setti Fatma) 2009} \\
\hline 1 & $\mathrm{U} / \mathrm{NE}$ & 72.91 & 52.019 & $95.26(0.292)$ & 25.60 \\
\hline 2 & $\mathrm{U} / \mathrm{C}$ & 109.7 & 96.63 & $153.846(0.133)$ & 41.35 \\
\hline 3 & $\mathrm{U} / \mathrm{C}$ & 87.18 & 126.88 & $113.125(0.222)$ & 30.40 \\
\hline Mean \pm SD & & & $91.843 \pm 37.66$ & $120.744 \pm 30(0.216)$ & $32.45 \pm 8$ \\
\hline \multicolumn{6}{|c|}{ Group 2 (Setti Fatma) 2013} \\
\hline 1 & $\mathrm{U} / \mathrm{NE}$ & 108.226 & 77.216 & $141.402(0.433)$ & 38.03 \\
\hline 2 & $\mathrm{U} / \mathrm{C}$ & 143.808 & 126.674 & $201.680(0.174)$ & 54.20 \\
\hline 3 & $\mathrm{U} / \mathrm{C}$ & 131.052 & 190.731 & $170.054(0.334)$ & 45.71 \\
\hline Mean \pm SD & & & $131.54 \pm 57$ & $171.045 \pm 30$ & $45.97 \pm 8$ \\
\hline \multicolumn{6}{|c|}{ Group 3 (Tamatert) 2009} \\
\hline 1 & $\mathrm{U} / \mathrm{C}$ & 44.73 & 87.65 & $15.203(0.278)$ & 14.58 \\
\hline 2 & $\mathrm{U} / \mathrm{C}$ & 35.39 & 83.38 & $17.635(0.137)$ & 16.91 \\
\hline 3 & $\mathrm{U} / \mathrm{C}$ & 54.44 & 93.38 & $18.698(0.378)$ & 0.36 \\
\hline Mean \pm SD & 2013 & & $88.137 \pm 5.02$ & $17.179 \pm 2(0.264)$ & $16.48 \pm 9$ \\
\hline \multicolumn{6}{|c|}{ Group 3 (Tamatert) 2013} \\
\hline 1 & $\mathrm{U} / \mathrm{C}$ & 62.278 & 122.037 & $21.167(0.387)$ & 20.30 \\
\hline 2 & $\mathrm{U} / \mathrm{C}$ & 55.974 & 131.876 & $27.892(0.217)$ & 26.75 \\
\hline 3 & $\mathrm{U} / \mathrm{C}$ & 104.469 & 179.195 & $35.881(0.725)$ & 34.44 \\
\hline Mean $\pm S D$ & & & $150.37 \pm 40.85$ & $28.313 \pm 7.36$ & $27.16 \pm 7$ \\
\hline \multicolumn{6}{|c|}{ Group 4 (Kissaria) $2009^{2}$} \\
\hline 1 & $\mathrm{U} / \mathrm{C}$ & 44.07 & 82 & $10.157(0.218)$ & 11.50 \\
\hline \multicolumn{6}{|l|}{2} \\
\hline \multicolumn{6}{|l|}{3} \\
\hline Mean \pm SD & & & 82 & $10.157(0.218)$ & 11.50 \\
\hline
\end{tabular}

${ }^{1} \mathrm{U}$, uniform; C, cosine; SP, simple polynomial; NE, negative exponential (Buckland et al., 2004).

${ }^{2}$ For this group only one of the models tested provided the best estimate.

sampling method, since the descriptive report of Cuzin (2008). The four groups detected in summer 2009 had been identified previously at the same sites (Cuzin, 2008). Regardless of counting methods, there were evident changes in group sizes and numbers of macaques observed between our study and that of Cuzin (2008). Groups 1 (Tourcht) and 4 (Kissaria) were present in summer 2009 but not in 2013; they may have exploited more favourable areas outside the surveyed area, perhaps in the adjacent valleys, following the chronic drought that occurred after 2009. Group 4 (Kissaria) was slightly larger in summer 2009 than in summer 1998 (12 vs 8 individuals). For group 2 (Setti Fatma) at least 100 individuals were recorded in 1983 and 46-60 individuals in 1997, reported by Drucker and Paine, respectively (cited in Cuzin, 2008). The large group size reported in the early 1980 (Cuzin, 2008) was probably a result of dynamic events (i.e. group fusion). Group 3 (Tamatert) was larger in summers 2009 and 2013 than in summers 2001, 2004 and
2007 ( 16 and 27 vs 10-11 individuals). Overall, the group size varied from 12 to 46 , which is comparable to that generally observed under natural conditions in Morocco (Deag, 1974; Taub, 1977; Fa, 1982). The smaller population size in summer 2013 (75-85 vs 122 individuals in 2009) could be attributable to either natural or human-caused mortalities, or emigration of macaques chased out of the valley by farmers in response to crop-raiding.

The population density varied with area, habitat type and time period (Table 3). The estimated mean density in the High Ourika was $10-171$ individuals $\mathrm{km}^{-2}$, depending on the group. The particularly high density estimates for group 2 (Setti Fatma) could be related to the relatively small surface area of the surrounding uncultivated lands occupied by macaques. A home range of 125 ha, which did not include the surrounding potentially exploited zones, namely waterfalls and the adjacent Tourcht valley, was reported for this group (Cuzin, 2008). The mean population density of 
TABLE 2 Results of ANOVA comparing density and population size of Barbary macaque groups in Setti Fatma and Tamatert, in the High Ourika valley, western High Atlas, Morocco (Fig. 1), in 2009 and 2013.

\begin{tabular}{|c|c|c|c|c|c|}
\hline & & Sum of squares & Degree of freedom & Mean square & $\mathrm{P}$ \\
\hline \multirow[t]{2}{*}{ Year } & Population size & 439.71 & 1 & 439.71 & 0.014789 \\
\hline & Density & $2,830.32$ & 1 & $2,830.32$ & 0.00001 \\
\hline \multirow[t]{2}{*}{ Locality } & Population size & 907.58 & 1 & 907.58 & 0.002152 \\
\hline & Density & $45,496.66$ & 1 & $45,496.66$ & 0.000009 \\
\hline \multirow[t]{2}{*}{ Year $\times$ locality } & Population size & 6.08 & 1 & 6.08 & 0.725432 \\
\hline & Density & $1,150.54$ & 1 & $1,150.54$ & 0.1551 \\
\hline \multirow[t]{2}{*}{ Error } & Population size & 367.36 & 8 & 45.92 & \\
\hline & Density & $3,736.36$ & 8 & 467.04 & \\
\hline
\end{tabular}

TABLE 3 Population and density estimates for the Barbary macaque in Algeria and Morocco since 1974.

\begin{tabular}{|c|c|c|c|}
\hline Location & Population/density & Year of survey & Source \\
\hline \multicolumn{4}{|l|}{ Algeria } \\
\hline Cedar-oak & 30 individuals $\mathrm{km}^{-2}$ & Unknown & Ménard et al. (1986) \\
\hline Oak & $7-30$ individuals $\mathrm{km}^{-2}$ & Unknown & $\mathrm{Fa}(1984)$ \\
\hline \multicolumn{4}{|l|}{ Morocco } \\
\hline \multirow[t]{4}{*}{ All forest types } & 17,000 individuals & Unknown & Taub (1975) \\
\hline & 10,000 individuals & 2002 & Camperio Ciani et al. (2003) \\
\hline & $6,000-10,000$ individuals & Unknown & Ross (2004) \\
\hline & 5,000 individuals & Unknown & Camperio Ciani (in van Lavieren \& Wich, 2010) \\
\hline \multicolumn{4}{|l|}{ Rif } \\
\hline \multirow[t]{4}{*}{ Oak/fir } & 6.73 individuals $\mathrm{km}^{-2}$ & $1982-1983$ & Mehlman (1989) \\
\hline & 249 individuals & 2010 & Waters et al. (2015) \\
\hline & 200 individuals & 1980 & $\mathrm{Fa}(1982)$ \\
\hline & 89 individuals & 2004 & Waters et al. (2007) \\
\hline \multicolumn{4}{|l|}{ Middle Atlas } \\
\hline \multirow[t]{4}{*}{ All forest types } & 70 individuals $\mathrm{km}^{-2}$ & 1968 & Deag $(1974,1984)$ \\
\hline & 43 individuals $\mathrm{km}^{-2}$ & 1977 & Taub (1977) \\
\hline & $21.3(12.1-28.2)$ individuals $\mathrm{km}^{-2}$ & 2005 & van Lavieren \& Wich (2010) \\
\hline & $9.2(0.2-23.4)$ individuals $\mathrm{km}^{-2}$ & $2007-2008$ & Ménard et al. (2013a,b) \\
\hline \multirow[t]{2}{*}{ Cedar } & $49.5-82.6$ individuals $\mathrm{km}^{-2}$ & 1994 & Camperio Ciani et al. (2005) \\
\hline & $9.3-14$ individuals $\mathrm{km}^{-2}$ & 2002 & Camperio Ciani et al. (2005) \\
\hline \multirow[t]{2}{*}{ Oak } & $9.4-19.3$ individuals $\mathrm{km}^{-2}$ & 1994 & Camperio Ciani et al. (2005) \\
\hline & $2.1-4.4$ individuals $\mathrm{km}^{-2}$ & 2002 & Camperio Ciani et al. (2005) \\
\hline \multirow[t]{2}{*}{ Cedar-oak } & $23.4-32.2$ individuals $\mathrm{km}^{-2}$ & 1994 & Camperio Ciani et al. (2005) \\
\hline & $5.2-16$ individuals $\mathrm{km}^{-2}$ & 2002 & Camperio Ciani et al. (2005) \\
\hline \multicolumn{4}{|l|}{ Western High Atlas } \\
\hline Oak & 43 individuals $\mathrm{km}^{-2}$ & $2009 ; 2013$ & This study \\
\hline \multirow[t]{3}{*}{ Global } & Up to 21,500 individuals & Unknown & Taub (1975) \\
\hline & $10,000-16,000$ individuals & 1992 & Lilly \& Mehlman (1993) \\
\hline & 15,000 individuals & Unknown & von Segesser et al. (1999) \\
\hline
\end{tabular}

Barbary macaques in the High Ourika valley (43 individuals $\mathrm{km}^{-2}$ ) is within the range of estimates reported $20-25$ years ago at Ain Kahla, Middle Atlas (36-44 individuals $\mathrm{km}^{-2}$; Taub, 1977; Fa, 1984). However, it is lower than that reported in 1968 (70 individuals $\mathrm{km}^{-2}$; Deag, 1974, 1984) and higher than more recent estimates for various areas in the Middle Atlas (Camperio Ciani et al., 2005; van Lavieren \& Wich, 2010; Ménard et al., 2013a,b).

The groups studied presented the multi-male and multifemale structure typical of the species (Fooden, 2007). The adult sex ratio in the population was balanced, as was also reported in Algeria (Ménard \& Vallet, 1993). However, this is above the range estimates for Macaca spp. (0.50o0.950; e.g. Sugiyama, 1971; Mukherjee \& Mukherjee, 1972; Simonds, 1973).

Overall, there were equal proportions of sexually mature and immature (juveniles and subadults) individuals in the studied population. This is comparable to $46-47 \%$ immature individuals reported in the western Rif range, in northern Morocco (Mehlman, 1989), and in Kabylie, Algeria (Ménard \& Vallet, 1993). According to the rule of Southwick et al. (1980), when the subpopulation of 
immature individuals is $<1.5$ times the subpopulation of adult females the population begins to decline, which may have occurred in the High Ourika, where the value is c. 1.2. However, the age structure of the population in the High Ourika indicates a demographically stable population, with pre-reproductive individuals comprising only $50-57 \%$ of the total population. These values are comparable to those reported for wild populations of other macaque species (Pirta et al., 1997; Okamoto et al., 2000; Kumara et al., 2010). A similar mean percentage was found in the Middle Atlas in nonprovisioned groups far from tourist sites (50\%) but a much lower value was found in groups near to tourist sites $(27 \%$; Ménard et al., 2013a,b). The recorded proportions were higher than those found in Middle Atlas populations in the 1970 s (44\%, calculated from Table 3 in Deag, 1974) and those in various habitat types in undisturbed sites in Algeria (43-47\%; Ménard et al., 1990; Ménard \& Vallet, 1993; Ménard, 2002).

The mean apparent fertility rate of 1.06 infants per adult female is slightly higher than the values reported in similar environments in Algeria (0.73-0.82; Ménard \& Vallet, 1993). This may be related to the availability of cultivated crops that supplement the diets of young, growing macaques with more abundant and energy-rich food resources, thus enhancing their survival rates.

The conservation of the small, peripheral population of Barbary macaques in degraded and fruit-poor natural environments in the High Ourika valley requires restoration of natural habitat and evaluation of the effects of human influences. We recommend (1) halting the clear-cutting of holm oaks, and restricting the number of sheep and goats within the forest patches, (2) restoring holm oak forests and favouring the expansion of new forests at higher altitudes, and (3) developing the local economy through an ecotourism project to compensate farmers for their crop losses. At a workshop in Marrakech in November 2015 we discussed these recommendations with the Administration of the Toubkal National Park, Regional Waters and Forests Service. The recommendations have been included in the regional strategic conservation action plan for the Barbary macaque in the High Ourika valley; the first two are about to be implemented, and a community-based ecotourism project is in preparation.

\section{Acknowledgements}

This study was part of a research project (2009-2015) funded by the Moroccan Service of Waters and Forests and the People's Trust for Endangered Species, UK. We thank the Association Amal Setti Fatma for their excellent support during field surveys.

\section{Author contributions}

$\mathrm{SN}, \mathrm{MZ}$ and MAAB conceived and designed the field work. $\mathrm{MAAB}$ conducted the line-transect surveys. SN and MAAB analysed the data. SN, MN, MA and JS provided field assistance. SM contributed materials and analysis tools. SN and $\mathrm{MZ}$ wrote the article.

\section{References}

Buckland, S.T., Anderson, D.R., Burnham, K.P. \& LaAke, J.L. (1993) Distance Sampling: Estimating Abundance of Biological Populations. Chapman \& Hall, London, UK.

Buckland, S.T., Anderson, D.R., Burnham, K.P., LaAke, J.L., Borchers, D.L. \& Thomas, L. (2001) Introduction to Distance Sampling: Estimating Abundance of Biological Populations. Oxford University Press, Oxford, UK.

Buckland, S.T., Anderson, D.R., Burnham, K.P., LaAke, J.L., Borchers, D.L. \& Thomas, L. (2004) Advanced Distance Sampling. Oxford: University Press, Oxford, UK.

Burnham, K.P., Anderson, D.R. \& LaAke, J.L. (1980) Estimation of density from line transect sampling of biological populations. Wildlife Monographs, 72, 3-202.

Butynski, T.M., Cortes, J., Waters, S., Fa, J., Hobbelink, M.E., VAn Lavieren, E. et al. (2008) Macaca sylvanus. The IUCN Red List of Threatened Species 2008: e.T12561A3359140. Http://dx.doi.org/10. 2305/IUCN.UK.2008.RLTS.T12561A3359140.en [accessed 16 July 2015].

Camperio Ciani, A., Palentini, L., Arahou, M., Martinoli, L., Capiluppi, C. \& Mouna, M. (2005) Population decline of Macaca sylvanus in the Middle Atlas of Morocco. Biological Conservation, $121,635-641$.

Camperio Ciani, A., Palentini, L. \& Mouna, M. (2003) The human dimension of the recent decline and possible recovery of the central Middle Atlas forest in Morocco. In Proceedings of the Workshop of Forest Landscape Restoration, Ifrane, Morocco, 27 May-1 June 2003.

CITES (2013) Species Database Report. Https://cites.org/fra/news/ sundry/2013/20131030_checklist.php [accessed 15 February 2013].

Cuzin, F. (2003) Les grands Mammifères du Maroc meridional (Haut Atlas, Anti Atlas, Sahara). Distribution, écologie et conservation. $\mathrm{PhD}$ thesis. EPHE, Montpellier II, Montpellier, France.

Cuzin, F. (2008) Étude bibliographique, écologique et démographique sur la population de singe magot (Macaca sylvanus) du Haut Ourika. DREF Haut Atlas Marrakech, PN du Toubkal, Marrakech, pp. 315374. Academic Press, London, UK, \& New York, USA.

DEAG, J.M. (1974) A study of the social behaviour and ecology of the wild Barbary macaque (Macaca sylvanus L.). PhD thesis. University of Bristol, UK.

DeAG, J.M. (1984) Demography of the Barbary macaque at Ain Kahla in the Moroccan Moyen Atlas. In The Barbary Macaque: A Case Study in Conservation (ed. J.E. Fa), pp. 113-134. Plenum Publishing Corporation, New York, USA.

El Alami, A., van Lavieren, E., Abou Fatima, R. \& Chait, A. (2013) A survey of the Endangered Barbary macaque Macaca sylvanus in the Central High Atlas Mountains of Morocco. Oryx, 47, 451-456.

FA, J.E. (1982) A survey of population and habitat of the Barbary macaque (Macaca sylvanus L.) in north Morocco. Biological Conservation, 24, 45-66.

FA, J.E. (1984) Habitat distribution and habitat preference in Barbary macaques (Macaca sylvanus L.). International Journal of Primatology, 5, 273-286.

Fooden, J. (2007) Systematic review of the Barbary macaque (Macaca sylvanus, Linnaeus, 1758). Fieldiana Zoology, 113, 1-60.

Glenn, M.E. (1998) Population density of Cercopithecus mona on the Caribbean Island of Grenada. Folia Primatologica, 69, 167-171. 
Glennie, R., Buckland, S.T. \& Thomas, L. (2015) The effect of animal movement on line transect estimates of abundance. PLoS ONE, 10(3), e0121333.

GonZalez-Kirchner, J.P. (1998) Group size and population density of the black howler monkey (Alouatta pigra) in Muchukux Forest, Quintana Roo, Mexico. Folia Primatologica, 69, 260-265.

Kumara, H.N., Singh, M., Kumar, S. \& Sinha, A. (2010) Distribution, abundance, group size and demography of dark-bellied bonnet macaque Macaca radiata radiata in Karnataka, South India. Current Science, 99, 663-667.

Lilly, A.A. \& Mehlman, P.T. (1993) Conservation update on the Barbary macaque. I. Declining distribution and population size in Morocco. American Journal of Primatology, 30, 327.

Mehlman, P.T. (1989) Comparative density, demography, and ranging behavior of Barbary macaques (Macaca sylvanus) in marginal and prime conifer habitats. International Journal of Primatology, 10, 269-292.

Ménard, N. (2002) Ecological plasticity of Barbary macaques (Macaca sylvanus). Evolutionary Anthropology, 11, 95-100.

Ménard, N. \& Vallet, D. (1993) Population dynamics of Macaca sylvanus in Algeria: an 8-year study. American Journal of Primatology, 30, 101-118.

Ménard, N., Vallet, D. \& Gautier-Hion, A. (1985) Démographie et reproduction de Macaca sylvanus dans différents habitats en Algérie. Folia Primatologica, 44, 65-81.

Ménard, N., Amroun, M., Mohamed-Said, R. \& Gautier-Rion, A. (1986) Status of the Barbary macaque (Macaca sylvanus) in Tikjda forest, Algéria. Primate Conservation, 7, 35-37.

Ménard, N., Foulquier, A., Vallet, D., Qarro, M., Le Gouar, P. \& Pierre, J.S. (2013a) How tourism and pastoralism influence population demographic changes in a threatened large mammal species. Animal Conservation, 17, 115-124.

Ménard, N., Hecham, R., Vallet, D., Chikhi, H. \& Gautier-Hion, A. (1990) Grouping patterns of a mountain population of Macaca sylvanus in Algeria-a fission-fusion system? Folia Primatologica, 55, 166-175.

Ménard, N., Yann, R., Adrien, F., Qarro, M., Chillasse, L., VALLET, D. et al. (2013b) Impact of human pressure and forest fragmentation on the Endangered Barbary macaque (Macaca sylvanus) in the Middle Atlas of Morocco. Oryx, 48, 276-284.

Mukherjee, R.P. \& Mukherjee, G.D. (1972) Group composition and population density of rhesus monkeys (Macaca mulatta (Zimmermann) in northern India. Primates, 13, 65-70.

Oкамото, K., Matsumura, S. \& Watanabe, K. (2000) Life history and demography of wild moor macaques (Macaca maurus): summary of ten years of observations. American Journal of Primatology, 52, 1-11.

Ounammou, A. (1986) Recherches sur l'étagement de la végétation dans le bassin versant de l'Ourika (Haut Atlas central, Maroc). Thèse zème cycle. Université Cadi Ayyad, Marrakech, Morocco.

Patterson, J.D. (2001) Primate Behavior: An Exercise Workbook, and edition. Waveland Press, Prospect Heights, USA.

Pirta, R.S., Gadgil, M. \& KharshiKar, A.V. (1997) Management of the rhesus monkey Macaca mulatta and Hanuman langur Presbytis entellus in Himachal Pradesh, India. Biological Conservation, 79, 97-106.

Riley, E.P., Suryobroto, B. \& Maestripieri, D. (2007) Distribution of Macaca ochreata and identification of mixed ochreata-tonkeana groups in south Sulawesi, Indonesia. Primate Conservation, 22, 129-133.

Ross, J.F. (2004) La foret de l'Atlas menacée par les singes? Courrier International, http://www.courrierinternational.com/article/2004/ 06/24/la-foret-de-l-atlas-menacee-par-les-singes [accessed 31 August 2016].
SimONDS, P.E. (1973) Outcast males and social structure among bonnet macaques (Macaca radiata). American Journal of Physical Anthropology, 38, 599-604.

Southwick, C.H., Richie, T., Taylor, H., Teas, J. \& Siddiqi, M.H. (1980) Rhesus monkey populations in India and Nepal: patterns of growth, decline, and natural regulation. In Biosocial Mechanisms of Population Regulation (eds M.N. Cohen, R.S. Malpass, H.G. Klein), pp. 151-170. Yale University Press, New Haven, USA.

Sugiyama, Y. (1971) Characteristics of the social life of bonnet macaques (Macaca radiata). Primates, 12, 247-266.

TAub, D.M. (1975) Notes and news. Oryx, 13, 229.

TAUB, D.M. (1977) Geographic distribution and habitat diversity of the Barbary macaque (Macaca sylvanus L.). Folia Primatologica, 27, 108-133.

Thomas, L., Buckland, S.T., Rexstad, E.A., LaAke, J.L., Strind berg, S., Hedley, S.L. et al. (2010) Distance software: design and analysis of distance sampling surveys for estimating population size. Journal of Applied Ecology, 47, 5-14.

Turckheim, G.D. \& Merz, E. (1984). Breeding Barbary macaques in outdoor open enclosures. In The Barbary Macaque: A Case Study in Conservation (ed. J.E. Fa), pp. 241-261. Plenum Publishing Corporation, New York, USA.

van Lavieren, E. \& Wich, S.A. (2010) Decline of the Endangered Barbary macaque (Macaca sylvanus) in the cedar forest of the Middle Atlas Mountains, Morocco. Oryx, 44, $133-138$.

von Segesser, F., Menard, N., Gaci, B. \& Martin, D. (1999) Genetic differentiation within and between isolated Algerian subpopulations of Barbary macaques (Macaca sylvanus): evidence from microsatellites. Molecular Ecology, 8, 433-442.

Wallace, R.B., Painter, R.L.E. \& Taber, A.B. (1998) Primate diversity, habitat preferences, and population density estimates in Noel Kempff Mercado National Park, Santa Cruz Department, Bolivia. American Journal of Primatology, 46, 197-211.

Waters, S., Aksissou, M., El Harrad, A., Hobbelink, M.E. \& Fa, J.E. (2007) Holding on in the Djebela: Barbary macaque Macaca sylvanus in northern Morocco. Oryx, 41, 106-108.

Waters, S., El Harrad, A., Chetuan, M. \& Amhaouch, Z. (2015) Barbary macaque group size and composition in Bouhachem Forest, North Morocco. African Primates, 10, 53-56.

\section{Biographical sketches}

Salwa Namous is working on the ecology and conservation of the Barbary macaque in the High Ourika valley, Morocco, and has a particular interest in human-macaque conflict. MoнAmmed ZNARI has been working on wildlife ecology and conservation biology for over 20 years, and is the curator of vertebrates at the Natural History Museum of Marrakech. Moulay Abdeljalil Ait BAAmRANE works on the ecology and conservation biology of the dorcas gazelle and Barbary macaque. Mohamed Naimi is interested in vertebrate ecology and has participated in projects on the dorcas gazelle and Barbary macaque. MoHAmed AoURIR is an ecologist and conservation biologist, whose research has focused on the ecology of various bird species, and more recently on mammals, in particular the Barbary macaque in the Ourika valley. Jan Siess is an ecologist and environmental educator. He initiated the ecotourism and conservation ecology project for the Barbary macaque in the High Ourika valley. Soraya Mokhtari is a forest and wildlife manager and the Director of the Toubkal National Park, Marrakech. 